\title{
Immobilization of Cyclooxygenase-2 on Silica Gel Microspheres: Optimization and Characterization
}

\author{
Qian Shi ${ }^{1,2}$, Junhui Chen ${ }^{2, *}$, Yanlong Wang ${ }^{2}$, Zhaoyong $\mathrm{Li}^{2}$, Xianguo Li ${ }^{1, *}$, Chengjun Sun ${ }^{2}$ \\ and Li Zheng ${ }^{2}$
}

Received: 4 August 2015 ; Accepted: 28 August 2015 ; Published: 5 November 2015

Academic Editor: Roberto Fernandez-Lafuente

1 College of Chemistry and Chemical Engineering, Ocean University of China, Qingdao 266100, China; srdwjm@sina.com

2 Research Center for Marine Ecology, The First Institute of Oceanography, State Oceanic Administration, Qingdao 266061, China; wangyanlong92@163.com (Y.W.); lizhaoyong2056@126.com (Z.L.); csun@fio.org.cn (C.S.); zhengli@fio.org.cn (L.Z.)

* Correspondence: jhchen@fio.org.cn (J.C.); lixg@ouc.edu.cn (X.L.); Tel.: +86-532-8896-6705 (J.C.); +86-532-6678-2215 (X.L.); Fax: +86-532-8896-3253 (J.C.); +86-532-6678-2540 (X.L.)

\begin{abstract}
In this study, immobilized COX-2 was successfully constructed through glutaraldehyde-mediated covalent coupling on functional silica gel microspheres. The optimum conditions, properties, and morphological characteristics of the immobilized COX-2 were investigated. The optimal immobilization process was as follows: about $0.02 \mathrm{~g}$ of aminated silica gel microspheres was activated by $0.25 \%$ GA solution for $6 \mathrm{~h}$ and mixed with $5 \mathrm{U}$ of free recombinant COX-2 solution. Then, the mixture was shaken for $8 \mathrm{~h}$ at $20^{\circ} \mathrm{C}$. Results showed that the immobilized COX-2 produced by this method exhibited excellent biocatalytic activity, equivalent to that of free COX-2 under the test conditions employed. The best biocatalytic activity of immobilized COX-2 appeared at $\mathrm{pH} 8.0$ and still maintained at about $84 \%(\mathrm{RSD}<7.39 \%, n=3)$ at $\mathrm{pH} 10.0$. For temperature tolerance, immobilized COX-2 exhibited its maximum biocatalytic activity at $40{ }^{\circ} \mathrm{C}$ and about $68 \%$ (RSD $<6.99 \%, n=3$ ) of the activity was maintained at $60{ }^{\circ} \mathrm{C}$. The immobilized COX-2 retained over $85 \%$ (RSD $<7.26 \%, n=3$ ) of its initial biocatalytic activity after five cycles, and after 10 days storage, the catalytic activity of immobilized COX-2 still maintained at about $95 \%$ (RSD $<3.08 \%, n=3$ ). These characteristics ensured the convenient use of the immobilized COX-2 and reduced its production cost.
\end{abstract}

Keywords: cyclooxyenase 2; immobilized enzyme; aminated silica gel; cross linking

\section{Introduction}

Multimetric enzyme-cyclooxygenase (prostaglandin endoperoxide $\mathrm{G} / \mathrm{H}$ synthase, COX) is a heme-containing enzyme that catalyzes the reaction of arachidonic acid (AA) to produce prostaglandins (PGs) [1]. The PGs present in many tissues can cause inflammation and pain. Undesirable PGs generated from arachidonic acid are mainly catalyzed by COX-2, which is an inducible COX isozyme that plays an important role in inflammation and tumor formation $[2,3]$. COX-2 also acts on the central nervous to cause hyperalgesia [4] and is related to the occurrence of nephropathy $[5,6]$. The enzyme has become an important drug target for the discovery and development of anti-inflammatory or anti-tumor drugs because selective inhibition of COX-2 may not only avoid the major side effects associated with COX-1 inhibition but also retain all of the benefits of classical non-steroidal anti-inflammatory drugs $[7,8]$. The discovery of COX-2-selective inhibitors is an important area of pharmaceutical research [9]. Development of a highly efficient in vitro assay method for screening COX-2-selective inhibitors is also a popular research topic. 
Over the last several decades, techniques for discovering COX-2-selective inhibitors, including high performance liquid chromatography [10], liquid chromatography-mass spectrometry (LC-MS) [7-9], ultrafiltration LC-MS [11,12], virtual screening methods [13,14], bioassays [13,15], and so on, have been increasingly reported. Some of these methods $[10,15]$ used cultured cell lines and were therefore time consuming and required special experimentation skills. The use of commercially available purified or recombinant COX-2 to screen COX-2-selective inhibitors has recently been expanded because assays using purified or recombinant enzymes are simpler, more convenient and less time consuming than cell-based assays. However, commercially available COX-2 is still very expensive, and cost is probably the core bottleneck limiting further applications of the in vitro assay method for screening COX-2-selective inhibitors. Using immobilized COX-2 instead of free COX-2 is crucial to overcome the shortcomings (e.g., high cost, non-recyclability, etc.) of free enzymes for screening COX-2-selective inhibitors in vitro.

Immobilized enzymes present many advantages over free enzymes, including reusability, long-time storage, low cost, and optimum $\mathrm{pHs}$ and temperatures that might be shifted to more suitable values, etc. [16-18]. The stabilization of immobilized enzymes increases when multipoint [17] or mutisubunit [19] immobilization occurs. Furthermore, the selectivity and specificity of immobilized enzymes may vary strongly under different experimental conditions [20]. To achieve these improvements of enzymes' properties via immobilization, new immobilization system (e.g., new materials, improved applications, visualize technique, etc.) and a deeper knowledge of the mechanisms of interaction between enzymes and activated solids both need to be developed [21]. The applications of affinity-immobilization technology, which is based on target-ligand binding interactions, have gradually matured over the years [22-24]. Previous successful research cases have encouraged us to develop a novel approach to immobilize COX-2 onto a suitable support. One of the simplest and most gentle coupling methods for enzyme immobilization involves reaction in an aqueous buffer by covalent attachment to water-insoluble carriers via glutaraldehyde (GA) because the buffer provides conditions close to the physiological $\mathrm{pH}$, ionic strength, and temperature [18]. There are two strategies for GA to intermolecularly crosslink enzyme molecules immobilized in supports. The first one is to adsorb the enzyme on the aminated support and then treat the enzyme-support composite with GA to activate all the primary amino groups of supports and the enzyme with just one GA molecule [25]. The second possibility is to use a pre-activated support [26]. With GA preactivated-supports, there are two GA molecules per amino group in the support which gives a quite reactive structure with the amino residues of the enzyme [27]. Different strategies used in experiment may affect the final effect of a chemical modification on the immobilization enzyme properties [28]. To date, only one article has mentioned the immobilization of COX-2 using magnetic particles as a carrier with GA as crosslinker, while the optimization of immobilized process and the characterization of immobilized COX-2 weren't discussed [7].

In the present study, functionalized porous $\mathrm{SiO}_{2}$ microspheres were prepared and COX-2 was immobilized on the surface of these microspheres with GA as crosslinker. Immobilization conditions, such as GA dosage, reaction $\mathrm{pH}$, reaction temperature and enzyme dosage were optimized, according to the relative activity of the immobilized COX-2, and the properties of the immobilized COX-2 were investigated.

\section{Results and Discussion}

\subsection{Optimization of the Immobilization Conditions}

Silica particles are hydrophilic, biocompatible, and stable in most biosystems [24]. Moreover, silica chemistry is fairly well known, and standard chemical protocols can be followed to conjugate various biomolecules to the silica surface $[18,29]$, which is an excellent solid support for enzyme immobilization [30,31]. $\mathrm{NH}_{2}$-modified $\mathrm{SiO}_{2}$ particles were chosen for the immobilization experiment in this study, and the immobilization conditions, including the dosage of the crosslinking agent, 
reaction $\mathrm{pH}$, reaction temperature, and enzyme dosage were optimized. The procedures for the preparation of $\mathrm{NH}_{2}$-modified $\mathrm{SiO}_{2}$ particles and the immobilization of COX-2 are illustrated in Scheme 1. From the scheme, we can see that GA doesn't react with enzyme inits free form, but as an unsaturated polymer, which gives imino bonds stabilized by conjugation [32]. The structure of the GA relevant for the modification of enzymes and supports is not a linear one, but some kind of fairly stable ring [33].

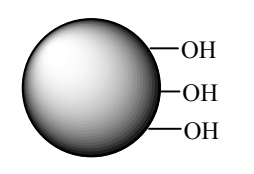

silica microsphere

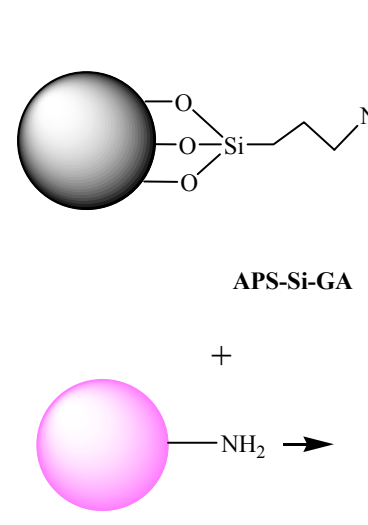

COX-2

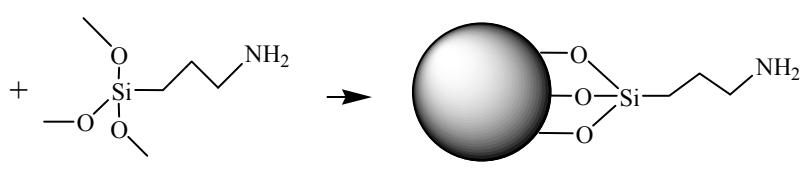

APS

APS-Si

$+$<smiles>CCCCCC(=O)NC</smiles>

GA

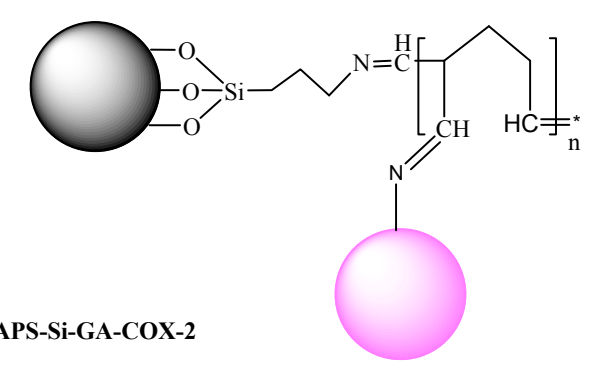

Scheme 1. Schematic of the synthesis of $\mathrm{NH}_{2}$-modified $\mathrm{SiO}_{2}$ particles and construction of the cross-linked immobilizedCOX-2 via GA chemistry (Schiff bases model).

\subsubsection{Effect of GA Concentration}

GA, a linear, 5-carbon dialdehyde is a pungent oily liquid which can be solubilized in water, as well as in organic solvents [34]. It reacts with amine groups at around neutral $\mathrm{pH}$ [35] and is more efficient than other aldehydes in generating thermally and chemically stable crosslinks [36]. The GA concentrations must be carefully investigated in order to obtain water-insoluble enzyme derivatives via crosslinking because low concentrations of enzyme and GA tend to induce intramolecular crosslinking by enhancing the probability that GA functional groups will react with the same enzyme molecule [18]. Thus, the effects of different final concentrations (i.e., $0.013 \%, 0.025 \%, 0.05 \%, 0.13 \%$, $0.25 \%$, and $0.5 \%, w / w)$ of GA in the buffer were evaluated. The effect of GA dosage during immobilization process on the activity of the immobilized COX-2 is shown in Figure 1. The relative activity of immobilized COX-2 increased as the concentration of GA increased in the range of $0.013 \%-0.25 \%$ and then decreased as the GA concentration exceeded $0.25 \%$. The results demonstrated that low GA concentrations are unable to provide sufficient aldehyde groups (crosslinkages) to react with the enzyme. By contrast, excess GA may produce steric hindrance and decrease the accessibility and accommodation of the substrate to the enzyme, which would lead to decreases in the relative activity of the immobilized enzyme $[18,34]$. Thus, the GA concentration was optimized to $0.25 \%$ in succeeding experiments. The relationship between GA concentration and relative activity was different from the literature [27]. This may be contribute to the high versatility that GA expressed in the process of immobilization, which greatly affect the final effect of a chemical modification on the immobilization enzyme properties [28]. 


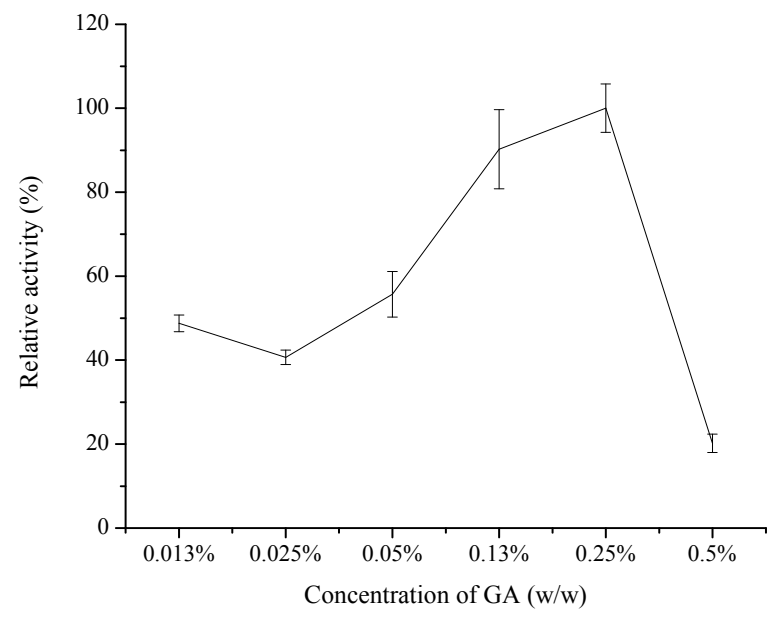

Figure 1. Effect of GA concentrations on the relative activity of the immobilized COX-2 $(n=3)$.

\subsubsection{Effect of Reaction Solution $\mathrm{pH}$}

The $\mathrm{pH}$ value is one of the key parameters that may turn subunit dissociation into the first step of the inactivation of multimeric enzymes [19]. During immobilization, improper solution $\mathrm{pH}$ can change the three-dimensional shape and activity of the enzymes [37], resulting in decreases in the relative activity of the immobilized enzyme. Hence, the effect of solution $\mathrm{pH}$ on the immobilized COX-2 was investigated by incubating the preparations in buffers of varying $\mathrm{pH}$ ranging from 6.0 to 8.0, as depicted in Figure 2A. The immobilized COX-2 exhibited maximum activity at $\mathrm{pH}$ 7.4. When the solution $\mathrm{pH}$ was less than 7.4, the immobilized COX-2 activity increased with increasing solution $\mathrm{pH}$ but decreased when $\mathrm{pH}>7.4$ because of enzyme inactivation [18]. Therefore, $\mathrm{pH} 7.4$ was selected as the best reaction solution $\mathrm{pH}$ for subsequent immobilization experiments.

\subsubsection{Effect of Reaction Temperature and Time}

Different immobilization temperatures affect the enzymatic reaction rate and protease denaturation. To examine the effect of reaction temperature on the relative activity of the immobilized COX-2, the reaction was performed at temperatures ranging from $10{ }^{\circ} \mathrm{C}$ to $37^{\circ} \mathrm{C}$ (Figure 2B). When the temperature was lower than $20^{\circ} \mathrm{C}$, the activity of the immobilized enzyme increased with increasing temperature, yielding an activity maximum at $20^{\circ} \mathrm{C}$. As the temperature further increased, the relative activity of the immobilized enzyme decreased because of enzyme inactivation at high temperatures.
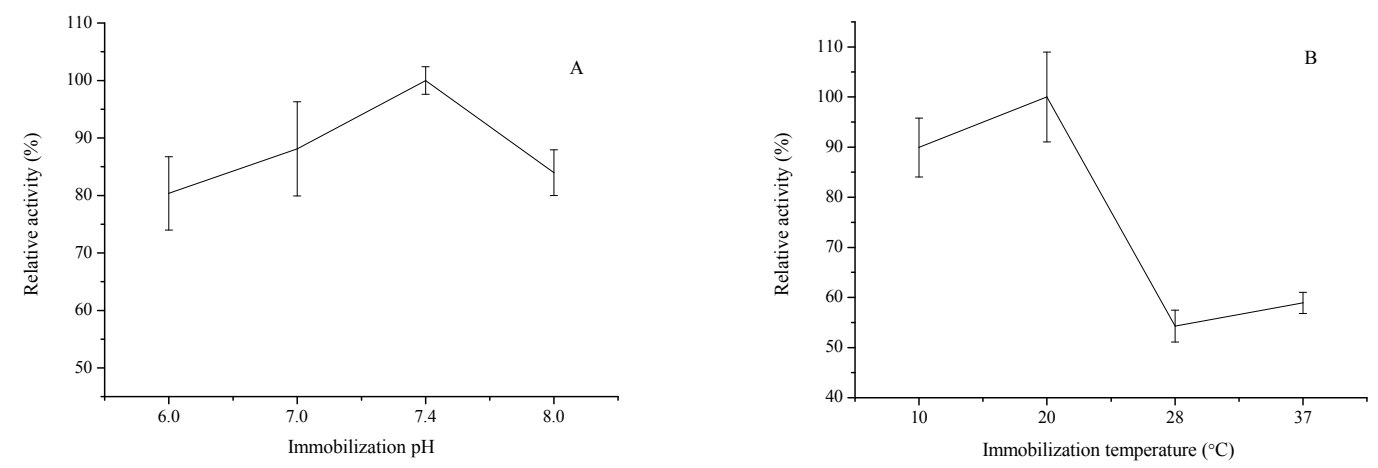

Figure 2. Cont. 

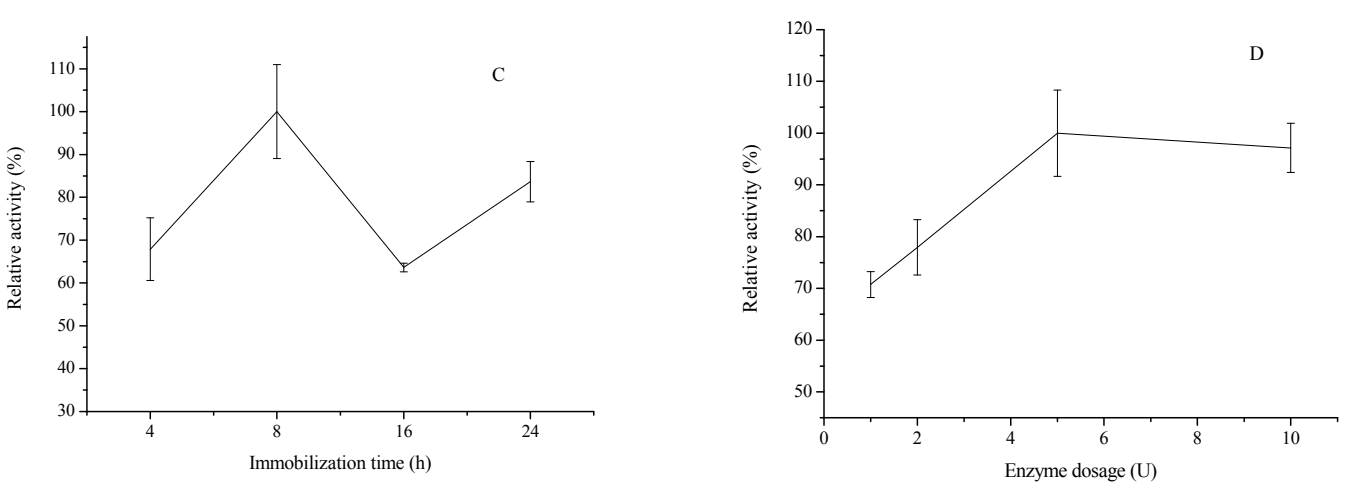

Figure 2. Effect of immobilization $\mathrm{pH}(\mathbf{A})$; reaction temperature (B); immobilization time (C) and enzyme dosage (D) on the relative activity of the immobilized COX-2 $(n=3)$.

The effects of reaction time on the relative activity of the immobilized COX-2 were also studied. The results shown in Figure $2 \mathrm{C}$ demonstrate that the relative activity of immobilized COX-2 is highest after $8 \mathrm{~h}$ of immobilization time. Consequently, the reaction temperature and time were optimized to $20^{\circ} \mathrm{C}$ and $8 \mathrm{~h}$, respectively, in succeeding experiments.

\subsubsection{Effect of Enzyme Dosage}

The dosage of free enzyme is an important parameter affecting enzyme immobilization. For multimeric enzymes, dissociation of enzyme subunits displays a direct dependence between enzyme concentration and enzyme stability [38,39]: enzyme stability increases with increasing of enzyme concentrations. However, with increasing free enzyme concentration, steric hindrance and non-specific adsorption also increase. Thus, the effect of free enzyme dosage on the relative activity of the immobilized COX-2 was investigated. As shown in Figure 2D, relative activity of immobilized COX-2 was only $70 \%$ (RSD $<2.49 \%, n=3$ ) when the dosage of COX-2 was $1 \mathrm{U}$. The immobilization proceeds better with increasing free COX-2 dosage, and the free COX-2 dosage ensuring optimum activity of immobilized COX-2 was be $5 \mathrm{U}$. Thus, the dosage of the free enzyme was optimized to $5 \mathrm{U}$ in subsequent experiment.

In summary, the optimum immobilization condition was as follows: about $0.02 \mathrm{~g}$ of aminated silica gel microspheres was activated by $0.25 \%$ GA solution for $6 \mathrm{~h}$ and mixed with $5 \mathrm{U}$ of free recombinant COX-2 solution after redundant GA removed. Then, the mixture was shaken for $8 \mathrm{~h}$ at $20{ }^{\circ} \mathrm{C}$. The immobilized COX-2 was separately washed with $3.5 \%(w / v) \mathrm{NaCl}$ solution, ultrapure water, and PBS thrice and then stored in $1 \mathrm{~mL}$ PBS at $4{ }^{\circ} \mathrm{C}$. Then free COX-2 was selected as control, and biocatalytic activity of the immobilized COX-2 obtained under the optimum immobilization condition was compared with that of free COX-2. Biocatalytic activity of the immobilized COX-2 was equivalent to that of free COX-2. The increase of activity may be due to the rigidification or un-aggregation of immobilized enzyme [40].

\subsection{Characterization}

Field emission scanning electron microscopy (FESEM) images of untreated and $\mathrm{NH}_{2}$-modified $\mathrm{SiO}_{2}$ particles before and after enzyme immobilization are displayed in Figure 3. The activated silica gel surface was uneven (Figure 3A), and the surface of APS-Si tended to be flat (Figure 3B). Figure 3C shows that some sheet-like materials appear on the surface of APS-Si-COX-2, thereby demonstrating that the free enzyme visibly bound to the carriers. 


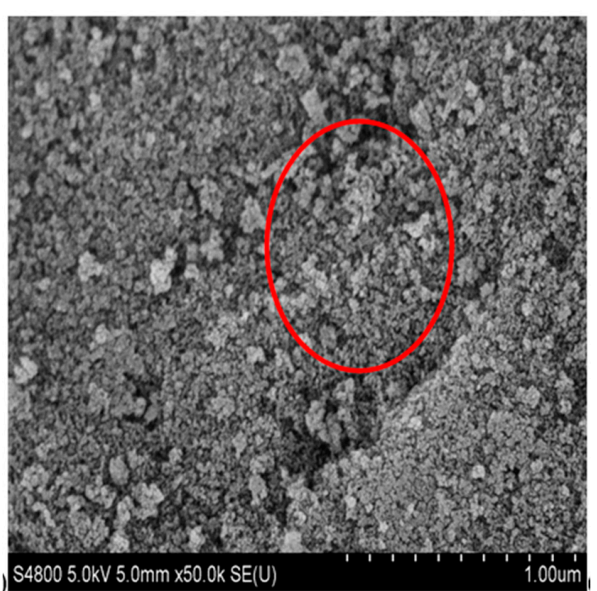

(A)

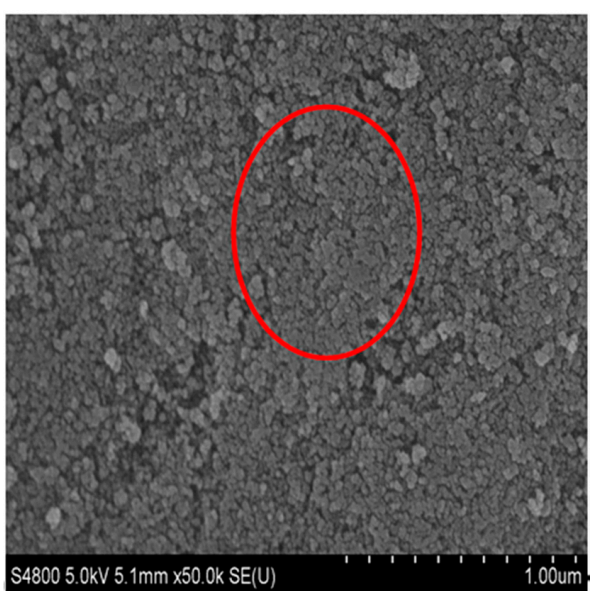

(B)

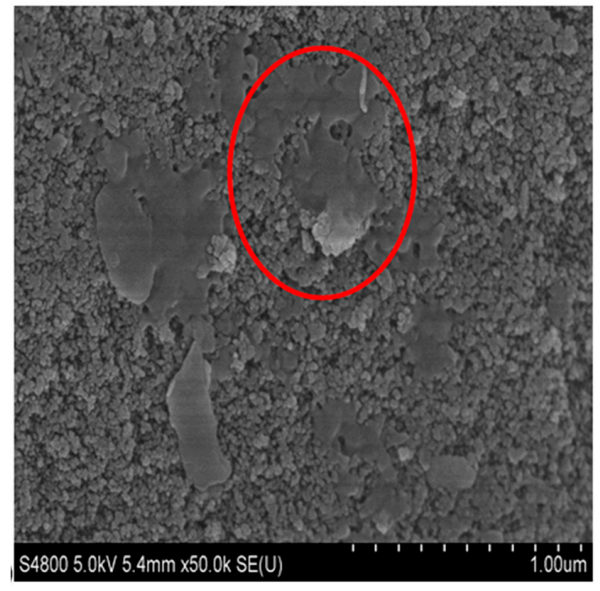

(C)

Figure 3. FESEM images of (A) the activated silica gel; (B) APS-Si; and (C) APS-Si-GA-COX-2.

\subsection{Properties of Immobilized Cyclooxyenase-2}

\subsubsection{Effect of Oscillation, $\mathrm{pH}$ and Temperature on the Biocatalytic Activity of Immobilized COX-2}

The biocatalytic activity of the immobilized enzyme is greatly dependent on the $\mathrm{pH}$, temperature, and status of the reaction solution. First, the effect of oscillation on the biocatalytic activity of the immobilized COX-2 was investigated. The reaction solution was placed understatic, gently shaken $(50 \mathrm{rpm})$, or vigorously shaken $(150 \mathrm{rpm})$ conditions at $37^{\circ} \mathrm{C}$ for $10 \mathrm{~min}$. As shown in Figure 4, gentle oscillation favored the biocatalytic reaction. Under the static and vigorous shaking conditions, the biocatalytic activities of the immobilized COX-2 were about $60 \%-70 \%$ of the activity observed in the gently shaken system.

Changes in $\mathrm{pH}$ can affect the enzyme conformation and degree of dissociation of the substrate, thereby affecting the binding and biocatalytic effects between enzyme molecules and the substrate [41]. In this study, the effects of reaction solution $\mathrm{pH}$ in the range of 4.0-10.0 on the biocatalytic activity of the free and immobilized COX-2 were studied, and relevant results are shown in Figure 5. 


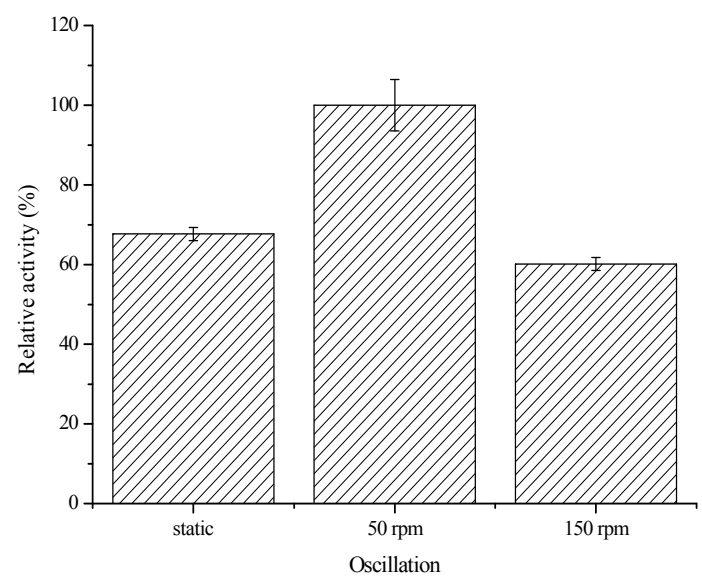

Figure 4. Effect of oscillation on the biocatalytic activity of the immobilized COX-2 $(n=3)$.

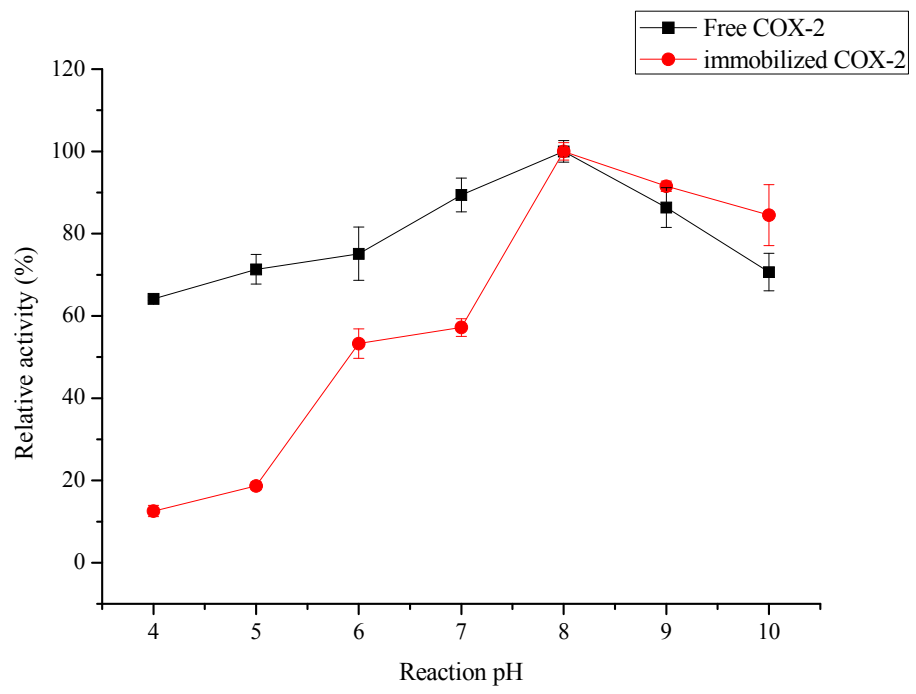

Figure 5. Effect of reaction $\mathrm{pH}$ on the biocatalytic activity of the immobilized COX-2 and free COX-2 $(n=3)$.

The immobilized COX-2 showed maximum biocatalytic activity at $\mathrm{pH}$ 8.0. Much lower or higher $\mathrm{pH}$ values led to decreases in the biocatalytic activity of the immobilized COX-2. Hereinto, acidic conditions affected the biocatalytic activity of immobilized COX-2 more than alkaline conditions. This is because of the Schiff bases formed under acidic and neutral conditions are unstable, regenerating both the aldehyde and the amino groups [33], but the fact that the biocatalytic activities of immobilized COX-2 still remain about $80 \%$ at $\mathrm{pH} 10.0$ demonstrates that the immobilized COX-2 had good tolerance for higher $\mathrm{pH}$ values. The relative activity of free COX-2 increased gently, almost the same as the immobilized COX-2. The immobilization process changed the $\mathrm{pH}$ tolerance of the enzyme; the biocatalytic activity of the immobilized COX-2 at pH 4 was $50 \%$ lower than that of free COX-2.

The temperature of the reaction solution is another important parameter affecting the biocatalytic activity of the immobilized enzyme. To examine the effect of temperature on its biocatalytic activity, the free and immobilized COX-2 was incubated in different temperatures (i.e., 10, 20, 30, 40, 50, and $60{ }^{\circ} \mathrm{C}$ ) for $10 \mathrm{~min}$, after which its biocatalytic activity was measured. As shown in Figure 6, the relative activity tendency of the free and immobilized COX-2 was almost the same. The optimum reaction temperature for both enzymes was $40{ }^{\circ} \mathrm{C}$. The reduction in the biocatalytic activity of free and immobilized COX-2 at lower or higher temperatures is associated with damage to the 
quaternary structure in the accessible surface area under extreme heating or cooling [42]. The free COX-2 was unable to maintain the biocatalytic activity at low temperature, only about $58 \%$ of the immobilized COX-2 at $10{ }^{\circ} \mathrm{C}$. The reason for the inactivation of free COX-2 is the dissociation of the enzyme subunits or the dissociation of the enzyme subunits or the loss of their correctly assembled structures [38,39]. In general, the immobilized COX-2 had a better relative activity than the free COX-2. The immobilized COX-2 exhibited around $60 \%$ of its maximum biocatalytic activity at temperatures ranging from $10{ }^{\circ} \mathrm{C}$ to $30{ }^{\circ} \mathrm{C}$. At $60{ }^{\circ} \mathrm{C}, 70 \%$ activity was still maintained by the immobilized COX-2. The activity of immobilized COX-2 under high temperature was better than that of free COX-2 was due to the immobilization-induced rigidification, which avoided distortion of the enzyme structure [40].

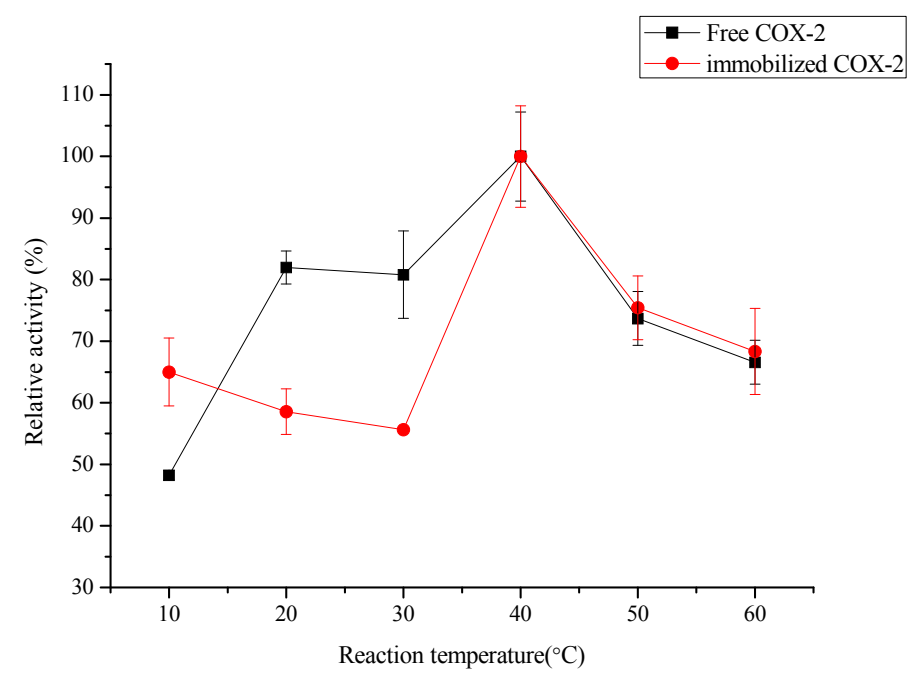

Figure 6. Effect of temperature on the biocatalytic activity of the immobilized COX-2 and free COX-2 $(n=3)$.

\subsubsection{Reusability and Storage Stability}

To expand the practical applications of immobilized enzymes, reusability is an important consideration [43]. To test its reusability, the immobilized COX-2 was reused seven times and its biocatalytic activity was recorded after each recovery. Figure 7 shows the relative biocatalytic activities of the immobilized COX-2 obtained after recycling; here, the initial biocatalytic activity is defined as $100 \%$. The immobilized COX-2 retained over $85 \%$ ( $\operatorname{RSD}<7.26 \%, n=3$ ) of its initial biocatalytic activity after five cycles and $60 \%$ (RSD $<8.12 \%, n=3$ ) of its initial biocatalytic activity after seven cycles, which indicates that it has appropriate stability and can be reused.

The storage stability of the immobilized COX-2 was further investigated over the course of 40 days. The free COX-2 was stored in storage solution and the immobilized COX-2 was stored in $0.1 \mathrm{~mol} / \mathrm{L}$ PBS solution at a temperature of $4{ }^{\circ} \mathrm{C}$. The results are presented in Figure 8 . About $66 \%$ activity of free COX-2 was lost during the first 10 days and the relative activity maintained in that value about 20 days. For immobilized COX-2, no significant loss of biocatalytic activity was observed after 5 days of storage, and over 95\% (RSD $<3.08 \%, n=3$ ) biocatalytic activity relative to its initial activity was observed on day 10; such activity is even better than that described in the literature [7]. The increased enzyme stability is attributed to enzyme rigidfication. COX-2 is a multimeric enzyme [44], and immobilization of COX-2 may involve multiple subunits, which prevents the enzyme dissociation [19]. With increasing storage time, the activity of the immobilized COX-2 gradually decreased. After 40 days of storage, the activity of the immobilized COX-2 dropped to below $60 \%$ of its initial activity. Overall, the immobilized COX-2 exhibited good storage stability, thereby ensuring its convenient and reduced production cost. 


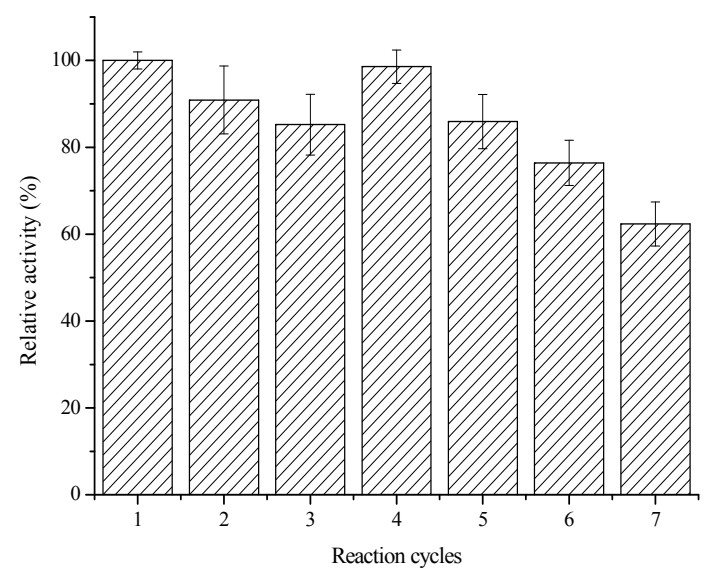

Figure 7. Reusability of the immobilized COX-2 $(n=3)$.

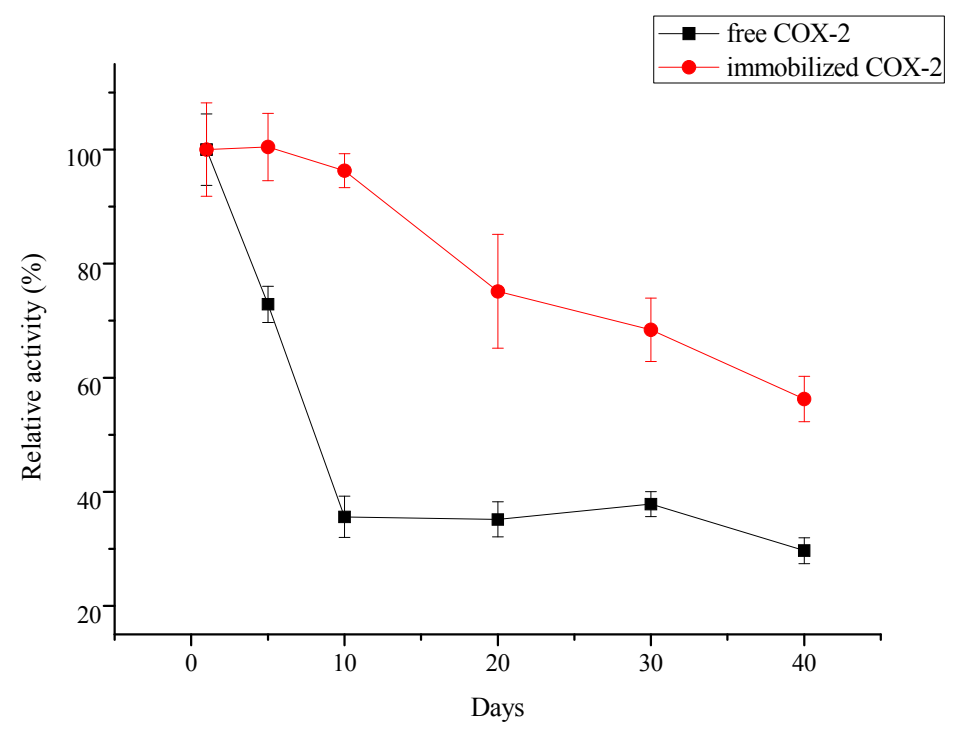

Figure 8. Storage stability of the immobilized COX-2 $(n=3)$.

\section{Experimental Section}

\subsection{Materials and Reagents}

$\mathrm{SiO}_{2}$ (grade 643, 200-425 mesh, $150 \AA$, 99\%, Davisil), human recombinant COX-2, arachidonic acid (AA), prostaglandin $\mathrm{E}_{2}\left(\mathrm{PGE}_{2}\right)$, and sodium diethyldithiocarbamate were purchased from Sigma (St. Louis, MO, USA). Tris (hydroxymethyl) aminomethane was purchased from J \& K Chemical (Beijing, China). HPLC-grade acetonitrile and methanol were purchased from ACS Company Inc. (Wilmingtong, DE, USA). $\gamma$-Aminopropyltrimethoxysilane (APS) was purchased from Alfa Aesar (Heysam, Lancs, UK). Purified water $(18.2 \Omega \mathrm{M})$ was prepared by using a Milli-Q water purification system (Millipore, Bedford, MA, USA). Phosphate buffer solution (100 mmol/L, pH 7.4) was selected and all other reagents used were of GR grade.

\subsection{Preparation of NH2-Modified Silica Microspheres}

Exactly $2.00 \mathrm{~g}$ of silica microspheres was boiled with $5 \% \mathrm{HCl}$ for $45 \mathrm{~min}$ to remove absorbed organic compounds on the surface of the particles. Rinsing with ultrapure water followed until the solution was of neutral $\mathrm{pH}$. After rinsing, the silica microspheres were dried at $80{ }^{\circ} \mathrm{C}$ for $24 \mathrm{~h}$. Aminated surfaces were manufactured according to our previous study [45]. Briefly, $0.50 \mathrm{~g}$ of 
activated silica microspheres was treated with $20 \mathrm{~mL}$ of $5 \%$ APS-toluene solution at $90{ }^{\circ} \mathrm{C}$ for $24 \mathrm{~h}$. The modified silica (APS-Si) was then rinsed with acetone to remove the physically absorbed silane coupling agent from the surface. After acetone volatilization, the APS-Si was dried at $110^{\circ} \mathrm{C}$ for $6 \mathrm{~h}$.

\subsection{Immobilization of Cyclooxyenase-2}

COX-2 storage solution was prepared with $80 \mathrm{mM}$ Tris- $\mathrm{HCl}, \mathrm{pH} 8.0$ with $0.1 \%$ TWEEN 20 and $300 \mu \mathrm{mol} / \mathrm{L}$ sodium diethyldithiocarbamate and 10\% glycerol. Free COX-2 was dissolved in storage solution to a final concentration of $100 \mathrm{U} / \mathrm{mL}$. The solid support $(0.02 \mathrm{~g})$ was dispersed in $2.0 \mathrm{~mL}$ of PBS for full swelling, after which $10 \mu \mathrm{L}$ of $50 \%(w / w)$ GA was added to give a final concentration of $0.25 \%(w / w)$. The APS-Si was reacted with GA at $28{ }^{\circ} \mathrm{C}$ for $6 \mathrm{~h}$ and then washed with an excess of ultrapure water to remove the redundant GA on the surface. The immobilization procedure was carried out by adding $1 \mathrm{~mL}$ of PBS and $50 \mu \mathrm{L}$ of COX-2 (5 U) to the GA-treated silica carrier at $20^{\circ} \mathrm{C}$ in a rocking incubator for $8 \mathrm{~h}$. The immobilized COX-2 was separately washed with $3.5 \%(w / v) \mathrm{NaCl}$ solution, ultrapure water, and PBS thrice to remove non-specifically bound COX-2 and stored in $1 \mathrm{~mL}$ PBS at $4{ }^{\circ} \mathrm{C}$ for further experimentation. Three replications of all assays were conducted in our study.

\subsection{Characterization}

A sputter coater (E-1045, Hitachi, Japan) was used to fabricate Au thin films. FESEM (S4800, Hitachi, Japan) was used to observe the morphology of the microspheres. A small amount of the samples (activated silica microspheres, APS-Si powder, and carrier bonded with the enzyme) was adhered to the sample holder and then coated with Au using the sputter coater. The treated silica samples were transferred to the FESEM sample pool to determine their surface morphological characteristics.

\subsection{Determination of Immobilized Cyclooxyenase-2 Activity}

The biocatalytic activity of immobilized COX-2 was determined according to the literature [9] with slight modifications. Briefly, in an Eppendorf tube, $4 \mu \mathrm{L}$ AA (500 mg/L) was added to $200 \mu \mathrm{L}$ of the immobilized enzyme, and the reaction was terminated at $37^{\circ} \mathrm{C}$ after $10 \mathrm{~min}$. Afterward, the generated $\mathrm{PGE}_{2}$ was extracted using $1500 \mu \mathrm{L}$ of hexane/ethyl acetate $(50: 50, v / v)$, and the extraction process was repeated another two times. The organic phase was removed, dried with nitrogen, and reconstituted in $100 \mu \mathrm{L}$ of methanol for analysis by using LC-MS/MS. The activity of immobilized enzyme based on the production of $\mathrm{PGE}_{2}$ under optimal condition was defined as $100 \%$, and relative activity was defined as the ratio of the yield of $\mathrm{PGE}_{2}$ in other conditions to that of optimum condition.

Chromatographic separation was performed on an analytical Agilent Poroshell120 C18 column $(2.7 \mu \mathrm{m} \times 3.0 \mathrm{~mm} \times 100 \mathrm{~mm}$; Agilent, Santa Clara, CA, USA), and the eluent was delivered by an Agilent 1200 HPLC system. The mobile phase for PGE $_{2}$ separation consisted of solvent A (water) and solvent B (acetonitrile); $5 \mathrm{~min}$ of isocratic elution of $0-5 \mathrm{~min}$ with $35 \% \mathrm{~B}$ was performed. The mobile phase flow rate was $0.4 \mathrm{~mL} / \mathrm{min}$ at room temperature and the injection volume was $10 \mu \mathrm{L}$.

A 6320 Series ion-trap mass spectrometer (Agilent Technologies, Wilmington, DE, USA) equipped with an ESI interface in negative mode was used to detect $\mathrm{PGE}_{2}$. The instrument was operated in full-scan and multiple reaction monitoring (MRM) modes. Other instrument parameters were as follows: scan range, $100-500 \mathrm{~m} / \mathrm{z}$; nebulizer pressure $\left(\mathrm{N}_{2}\right), 35$ psi; drying gas $\left(\mathrm{N}_{2}\right)$, $11 \mathrm{~L} / \mathrm{min}$; and drying gas temperature, $325^{\circ} \mathrm{C}$. The deprotonated molecules of $[\mathrm{M}-\mathrm{H}]^{-}(\mathrm{m} / z$ 351) corresponding to $\mathrm{PGE}_{2}$ were selected for collision-induced dissociation at a collision energy of $1.0 \mathrm{~V}$. During MRM, three fragment ions of $m / z$ 333, 315, and 271 were acquired; these ions correspond to $\left[\mathrm{M}-\mathrm{H}-\mathrm{H}_{2} \mathrm{O}\right]^{-},\left[\mathrm{M}-\mathrm{H}-2 \mathrm{H}_{2} \mathrm{O}\right]^{-}$, and $\left[\mathrm{M}-\mathrm{H}-2 \mathrm{H}_{2} \mathrm{O}-\mathrm{CO}_{2}\right]^{-}$, respectively. $\mathrm{PGE}_{2}$ was measured by recording the signal for the deprotonated molecules of $m / z 351$ to fragment ion of $m / z 333$. 


\subsection{Reusability of Immobilized Enzyme}

After each assay, the immobilized COX-2 was taken out from the reaction medium by centrifugation and was washed separately with $3.5 \% \mathrm{NaCl}$, ultra-pure water, and phosphate buffered saline (PBS, $0.1 \mathrm{~mol} / \mathrm{L}, \mathrm{pH} 7.4$ ) thrice to remove the substrate and adhered products. The immobilized enzyme recovered by this procedure was used repeatedly. The activity determined for the first time was considered as control (100\%) for the calculation of remaining percentage activity after each use.

\section{Conclusions}

In this study, functionalized $\mathrm{SiO}_{2}$ microspheres were prepared and COX-2 was successfully immobilized on the surface of $\mathrm{NH}_{2}$-modified $\mathrm{SiO}_{2}$ particles by using GA as the crosslinking agent. The proposed immobilized COX-2 exhibited good reusability and storage stability. The activity of the immobilized COX-2 exceeded $60 \%$ of its initial biocatalytic activity after seven cycles of reuse. These results demonstrate the efficient use and low cost of the immobilized COX-2. The immobilized COX-2 proposed in this work may be used as an enzyme catalyst for the enzymatic transformation of AA and facilitate the development of other in vitro assay methods for screening of COX-2-selective inhibitors.

Acknowledgments: The researchers gratefully acknowledge the financial support from the National Natural Scientific Foundation of China (20905017), the Basic Scientific Fund for National Public Research Institutes of China (2014T05), the Shandong Provincial Natural Science Foundation (ZR2015PD003), China, the Open Research Fund Program of Key Laboratory of Marine Drugs (Ocean University of China), Ministry of Education (KLMD (OUC) 201306) and the 2012 Taishan Scholar for funding support.

Author Contributions: Qian Shi, Yanlong Wang and Zhaoyong Li performed the main experimental work and analyzed the data. Junhui Chen and Xianguo Li designed the experiment, wrote the paper and revised the manuscript. Chengjun Sun conducted the LC-MS/MS measurement, and also revised the manuscript. Li Zheng prepared the figures and tables.

Conflicts of Interest: The authors declare no conflict of interest.

\section{References}

1. Nikolic, D.; Habibi-Goudarzi, S.; Corley, D.G.; Gafner, S.; Pezzuto, J.M.; van Breemen, R.B. Evaluation of cyclooxygenase-2 inhibitors using pulsed ultrafiltration mass spectrometry. Anal. Chem. 2000, 72, 3853-3859. [CrossRef] [PubMed]

2. Seibert, K.; Zhang, Y.; Leahy, K.; Hauser, S.; Masferrer, J.; Perkins, W.; Lee, L.; Isakson, P. Pharmacological and biochemical demonstration of the role of cyclooxygenase-2 in inflammation and pain. Proc. Natl. Acad. Sci. USA 1994, 91, 12013-12017. [CrossRef] [PubMed]

3. Gately, S.; Li, W.W. Multiple roles of COX-2 in tumor angiogenesis: A target for antigiogenic therapy. Semin. Oncol. 2004, 31, 2-11. [CrossRef] [PubMed]

4. Samad, T.A.; Moore, K.A.; Sapirstein, A.; Billet, S.; Allchorne, A.; Poole, S.; Bonventre, J.V.; Woolf, C.J. Interleukin-1 beta-mediated induction of COX-2 in the CNS contributes to inflammatory pain hypersensitivity. Nature 2001, 410, 471-475. [CrossRef] [PubMed]

5. Catella-Lawson, F.; McAdam, B.; Morrison, B.W.; Kapoor, S.; Kujubu, D.; Antes, L.; Lasseter, K.C.; Quan, H.; Gertz, B.J.; FitzGerald, G.A. Effects of specific inhibition of cyclooxygenase-2 on sodium balance, hemodynamics, and vasoactive eicosanoid. J. Pharmacol. Exp. Ther. 1999, 289, 735-741. [PubMed]

6. Dinchuk, J.E.; Car, B.D.; Focht, R.J.; Johnston, J.J.; Jaffee, B.D.; Covington, M.B.; Contel, N.R.; Eng, V.M.; Collins, R.J.; Czerniak, P.M.; et al. Renal abnormalities and an altered inflammatory response in mice lacking cyclooxygenase II. Nature 1995, 378, 406-409. [CrossRef] [PubMed]

7. Deng, X.; Shi, S.; Li, S.; Yang, T. Magnetic ligand fishing combination with high-performance liquid chromatography-diode array detector-mass spectrometry to screen and characterize cyclooxygenase-2 inhibitors from green tea. J. Chromatogr. B Anal. Technol. Biomed. Life Sci. 2014, 973C, 55-60. [CrossRef] [PubMed]

8. Zhu, H.; Zhuang, X.; Liu, S.; Pi, Z.; Song, F.; Lin, N.; Liu, Z. Ultrahigh-performance liquid chromatography/tandem mass spectrometry method for evaluating enzyme activity and screening inhibitors of cyclooxygenase-2. Rapid Commun. Mass Spectrom. 2014, 28, 1792-1800. [CrossRef] [PubMed] 
9. Cao, H.; Yu, R.; Tao, Y.; Nikolic, D.; van Breemen, R.B. Measurement of cyclooxygenase inhibition using liquid chromatography-tandem mass spectrometry. J. Pharm. Biomed. Anal. 2011, 54, 230-235. [CrossRef] [PubMed]

10. Dannhardt, G.; Ulbrich, H. In-vitro test system for the evaluation of cyclooxygenase-1 (COX-1) and cyclooxygenase-2 (COX-2) inhibitors based on a single HPLC run with UV detection using bovine aortic coronary endothelial cells (BAECs). Inflamm. Res. 2001, 50, 262-269. [CrossRef] [PubMed]

11. Van Breemen, R.B.; Tao, Y.; Li, W. Cyclooxygenase-2 inhibitors in ginger (Zingiberofficinale). Fitoterapia 2011, 82, 38-43. [CrossRef] [PubMed]

12. Zhu, H.; Liu, S.; Li, X.; Song, F.; Liu, Z.; Liu, S. Bioactivity fingerprint analysis of cyclooxygenase-2 ligands from radix Aconiti by ultrafiltration-UPLC-MSn. Anal. Bioanal. Chem. 2013, 405, 7437-7445. [CrossRef] [PubMed]

13. Li, Y.; Frenz, C.M.; Chen, M.; Wang, Y.; Li, F.; Luo, C.; Liang, N.; Yang, H.; Bohlin, L.; Wang, C. Primary virtual and in vitro bioassay screening of natural Inhibitors from flavonoids against COX-2. Chin. J. Nat. Med. 2011, 9, 156-160.

14. Chen, Y.C. De novo design of novel selective COX-2 inhibitors: From virtual screening to pharmacophore analysis. J. Taiwan Inst. Chem. Eng. 2009, 40, 55-69. [CrossRef]

15. Laufer, S.; Zechmeister, P.; Klein, T. Development of an in vitro test system for the evaluation of cyclooxygenase-2 inhibitors. Inflamm. Res. 1999, 48, 133-138. [CrossRef] [PubMed]

16. Mohamed, S.A.; Khan, J.A.; Al-Bar, O.A.; El-Shishtawy, R.M. Immobilization of Trichoderma harzianum $\alpha$-Amylase on Treated Wool: Optimization and Characterization. Molecules 2014, 19, 8027-8038. [CrossRef] [PubMed]

17. Iyer, P.V.; Ananthanarayan, L. Enzyme stability and stabilization-Aqueous and non-aqueous environment. Process Biochem. 2008, 43, 1019-1032. [CrossRef]

18. Chang, Q.; Tang, H. Immobilization of Horseradish Peroxidase on $\mathrm{NH}_{2}$-Modified Magnetic $\mathrm{Fe}_{3} \mathrm{O}_{4} / \mathrm{SiO}_{2}$ Particles and Its Application in Removal of 2,4-Dichlorophenol. Molecules 2014, 19, 15768-15782. [CrossRef] [PubMed]

19. Fernandez-Lafuente, R. Stabilization of multimeric enzymes: Strategies to prevent subunit dissociation. Enzyme Microb. Technol. 2009, 45, 405-418. [CrossRef]

20. Mateo, C.; Palomo, J.M.; Fernandez-Lorente, G.; Guisan, J.M.; Fernandez-Lafuente, R. Improvement of enzyme activity, stability and selectivity via immobilization techniques. Enzyme Microb. Technol. 2007, 40, 1451-1463. [CrossRef]

21. Fernández-Lafuente, R. Editorial: Special issue-enzyme immobilization. Molecules 2014, 19, $20671-20674$. [CrossRef] [PubMed]

22. Kondo, A.; Teshima, T. Preparation of immobilized enzyme with high activity using affinitytag based on proteins A and G. Biotechnol. Bioeng. 1995, 46, 421-428. [CrossRef] [PubMed]

23. Mateo, C.; Fernández-Lorente, G.; Pessela, B.C.; Vian, A.; Carrascosa, A.V.; Garcia, J.L.; Fernández-Lafuente, R.; Guisan, J.M. Affinity chromatography of polyhistidine tagged enzymes-New dextran-coated immobilized metal ion affinity chromatography matrices for prevention of undesired multipoint adsorptions. J. Chromatogr. A 2001, 915, 97-106. [CrossRef]

24. Yang, Y.; Li, J.; Zhang, Y. Characterization of the diatomite binding domain in the ribosomal protein L2 from E. coli and functions as an affinity tag. Appl. Microbiol. Biotechnol. 2013, 97, 2541-2549.

25. López-Gallego, F.; Betancor, L.; Mateo, C.; Hidalgo, A.; Alonso-Morales, N.; DellamoraOrtiz, G.; Guisán, J.M.; Fernández-Lafuente, R. Enzyme stabilization by glutaraldehyde crosslinking ofadsorbed proteins on aminated supports. J. Biotechnol. 2005, 119, 70-75. [CrossRef] [PubMed]

26. Betancor, L.; López-Gallego, F.; Hidalg, A.; Alonso-Morales, N.; Mateo, G.D.; Fernández-Lafuente, R.; Guisán, J.M. Different mechanisms of protein immobilization on glutaraldehyde activated supports: Effect of support activation and immobilization conditions. Enzyme Microb. Technol. 2006, 39, 877-882. [CrossRef]

27. Monsan, P. Optimization of glutaraldehyde activation of a support for enzyme immobilization. J. Mol. Catal. 1978, 3, 371-384. [CrossRef]

28. Barbosa, O.; Torres, R.; Ortiz, C.; Fernandez-Lafuente, R. Versatility of glutaraldehyde to immobilize lipases: Effect of the immobilization protocol on the properties of lipase B from Candida antarctica. Process Biochem. 2012, 47, 1220-1227. [CrossRef] 
29. Ma, D.; Guan, J.; Normandin, F.; Dénommée, S.; Enright, G.; Veres, T.; Simard, B. Multifunctional nano-architecture for biomedical applications. Chem. Mater. 2006, 18, 1920-1927. [CrossRef]

30. Solís, S.; Paniagua, J.; Martínez, J.C.; Asomoza, M. Immobilization of papain on mesoporous silica: $\mathrm{pH}$ effect. J. Sol-Gel Sci. Technol. 2006, 37, 125-127. [CrossRef]

31. Aissaoui, N.; Bergaoui, L.; Boujday, S.; Lambert, J.-F.; Méthivier, C.; Landoulsi, J. Enzyme immobilization on silane-modified surface through short linkers: Fate of interfacial phases and impact on catalytic activity. Longmuir 2014, 30, 4066-4077. [CrossRef] [PubMed]

32. Monsan, P.; Puzo, G.; Mazarguil, H. Étude du mécanisme d' établissement des liaisons glutaraldéhyde-protéines. Biochimie 1975, 57, 1281-1292. [CrossRef]

33. Barbosa, O.; Ortiz, C.; Berenguer-Murcia, Á.; Torres, R.; Rodrigues, R.C.; Fernandez-Lafuente, R. Glutaraldehyde in bio-catalysts design: A useful crosslinker and a versatile tool in enzyme immobilization. RSC Adv. 2014, 4, 1583-1600. [CrossRef]

34. Migneault, I.; Dartiguenave, C.; Bertrand, M.J.; Waldron, K.C. Glutaraldehyde: Behavior in aqueous solution, reaction with proteins, and application to enzyme crosslinking. Biotechniques 2004, 37, 790-796, 798-802. [PubMed]

35. Okuda, K.; Urabe, I.; Yamada, Y.; Okada, H. Reaction of glutaraldehyde with amino and thiol compounds. J. Ferment. Bioeng. 1991, 71, 100-105. [CrossRef]

36. Nimni, M.E.; Cheung, D.; Strates, B.; Kodama, M.; Sheikh, K. Chemically modified collagen: A natural biomaterial for tissue replacement. J. Biomed. Mater. Res. 1987, 21, 741-771. [CrossRef] [PubMed]

37. Tümtürk, H.; Sahin, F.; Demirel, G. A new method for immobilization of acetylcholinesterase. Bioprocess Biosyst. Eng. 2007, 30, 141-145. [CrossRef] [PubMed]

38. Poltorak, O.M.; Chukhrai, E.S.; Kozlenkov, A.A.; Chaplin, M.F.; Trevan, M.D. The putative common mechanism for inactivation of alkaline phosphatase isoenzymes. J. Mol. Catal. B Enzym. 1999, 7, 157-163. [CrossRef]

39. Phlipenko, O.S.; Atyaksheva, L.F.; Pltorak, O.M.; Chukhrai, E.S. Dissociation and catalytic activity of oligomer forms of $\beta$-galactosidases. Russ. J. Phys. Chem. A 2007, 81, 990-994. [CrossRef]

40. Rodrigues, R.C.; Ortiz, C.; Berenguer-Murcia, A.; Torres, R.; Fernández-Lafuente, R. Modifying enzyme activity and selectivity by immobilization. Chem. Soc. Rev. 2013, 42, 6290-6307. [CrossRef] [PubMed]

41. Wang, Q.; Cui, J.; Li, G.; Zhang, J.; Li, D.; Huang, F.; Wei, Q. Laccase Immobilized on a PAN/Adsorbents Composite Nanofibrous Membrane for Catechol Treatment by a Biocatalysis/Adsorption Process. Molecules 2014, 19, 3376-3388. [CrossRef] [PubMed]

42. Jaenicke, R.; Bohm, G. The stability of proteins in extreme environments. Curr. Opin. Struct. Biol. 1998, 8, 738-748. [CrossRef]

43. Abaházi, E.; Boros, Z.; Poppe, L. Additives enhancing the catalytic properties of lipase from burkholderiacepacia immobilized on mixed-function-grafted mesoporous silica gel. Molecules 2014, 19, 9818-9837. [CrossRef] [PubMed]

44. Chapman, E.G.; Piontkivska, H.; Walker, J.M.; Stewart, D.T.; Curole, J.P.; Hoeh, W.R. Extreme primary and secondary protein structure variability in the chimeric male-transmitted cytochrome c oxidase subunit II protein in freshwater mussels: Evidence for an elevated amino acid substitution rate in the face of domain-specific purifying selection. BMC Evol. Biol. 2008, 8, 165-180. [PubMed]

45. Chen, J.; Shi, Q.; Chen, C.; Li, X.; Cao, W.; Zheng, L.; Wang, X. Preparation and characteristic research of immobilized acetylcholinesterase. Acta Chim. Sin. 2012, 70, 624-628. [CrossRef]

Sample Availability: Samples of soluble and immobilized cyclooxygenase-2 are available from the authors.

(C) 2015 by the authors; licensee MDPI, Basel, Switzerland. This article is an open access article distributed under the terms and conditions of the Creative Commons by Attribution (CC-BY) license (http://creativecommons.org/licenses/by/4.0/). 